Check for updates

London, UK

Cite this as: BMJ2020;370:m2839 http://dx.doi.org/10.1136/bmj.m2839 Published: 14 July 2020

\section{Covid-19: Experts criticise claim that remdesivir cuts death rates}

\section{Michael Day}

Experts have criticised pharmaceutical firm Gilead Sciences after it released data suggesting that its antiviral drug remdesivir can reduce death rates for patients with covid-19. They say the research is intrinsically flawed and that the claimed benefits are overhyped and inappropriately promoted in press releases.

The California based company said intravenous remdesivir reduced mortality by $62 \%$ compared with standard treatment in the SIMPLE trial of 1132 mainly US patients. Its data showed that $7.6 \%$ of covid-19 patients treated with the drug died compared with $12.5 \%$ of control patients.

Crucially, however, the study compared treatment and non-treatment groups in different cohorts treated in different conditions. The remdesivir patients were compared with a historical group of more than 800 patients on the "standard of care" of other drugs and oxygen.

Experts were quick to dismiss the significance of the results.

Martin Landray, professor of medicine and epidemiology at the University of Oxford and the lead research of the RECOVERY trial comparing treatments for covid-19, said, "What has been reported is an association-the results of comparing two rather different groups of patients. It's impossible to draw any conclusions about the true effects of remdesivir on survival. For that we need robust evidence from large randomised controlled trials-and we simply don't have that yet."

Merdad Parsey, Gilead's chief medical officer, said in a statement, "We are working to broaden our understanding of the full utility of remdesivir. We are sharing data with the research community as quickly as possible with the goal of providing transparent and timely updates on new developments with remdesivir."

Mainstream media were quick to report that the drug had been linked to a significant reduction in death rates. Within hours of the announcement on 10 July, Gilead's share price rose $3 \%$. The company has said that it will charge health systems in developed countries around €1900 (€2090; \$2400) for a five day course of remdesivir.

In May, The BMJ reported that some NHS patients in hospital with covid-19 would be able to receive remdesivir, supplied at no cost by Gilead, under the Emergency Access to Medicines Scheme. ${ }^{1}$ A spokeswoman from the Department of Health and Social Care told The BMJ this week that it was unable to say how many NHS patients have received the drug because the data were commercially sensitive.

The decision to make it available to NHS patients was prompted by a report in the New England Journal of Medicine suggesting that remdesivir shortened the time to recovery by about four days. ${ }^{2}$ However, that data also proved controversial because the trial was stopped early and provided only preliminary results. In addition, it emerged that the primary clinical outcome had been changed after patients were randomised.

On the same day the NEJM study was published, the Lancet reported randomised, double blind, placebo controlled data from Chinese medics that suggested remdesivir showed no significant benefits in speeding recovery from covid-19 or reducing mortality. ${ }^{3}$

Stephen Evans, professor of pharmacoepidemiology at the London School of Hygiene and Tropical Medicine, said the hype over the SIMPLE data once again raised ethical questions over Gilead's promotion of remdesivir as a covid-19 treatment. He said the firm's "approach to obtaining proper randomised trial evidence for the efficacy, especially in terms of mortality, of remdesivir has been below the standards I would expect of a large ethical pharmaceutical company."

He added, "Their first approach was only to sponsor trials where both arms received remdesivir and they have relied on other sponsors to carry out the higher standard of trial to evaluate remdesivir. They have consistently released information through press releases rather than waiting for at least a preprint of the trial report. The strong randomised evidence does suggest that remdesivir will reduce mortality, but there is a danger of this being exaggerated, especially when the only information is in a press release."

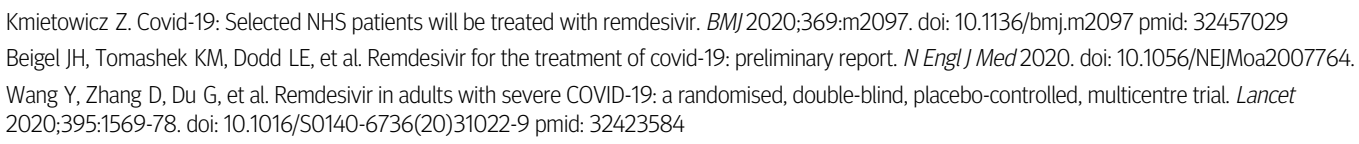

This article is made freely available for use in accordance with BMJ's website terms and conditions for the duration of the covid-19 pandemic or until otherwise determined by BMJ. You may use, download and print the article for any lawful, non-commercial purpose (including text and data mining) provided that all copyright notices and trade marks are retained. 